
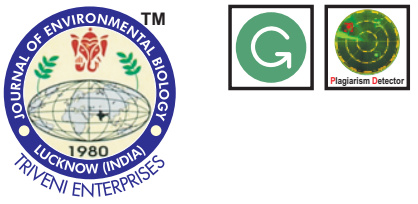

\title{
Positive aspects of studying the sedimentations in reservoirs through the natural experiments
}

\section{Authors Info \\ L. Matchavariani ${ }^{1 *}$, G. Metreveli ${ }^{2}$, L. Lagidze ${ }^{3}$, Z. Gulashvili ${ }^{4}$, D. Svanadze and N. Paichadze ${ }^{3}$ 'Department of Soil Geography, Faculty of Exact and Natural Sciences, Tbilisi State University, 0179, Tbilisi, Georgia \\ ${ }^{2}$ Institute of Applied Ecology, \\ Faculty of Exact \& Natural \\ Sciences, Tbilisi State University, 0179, Tbilisi, Georgia \\ ${ }^{3}$ Department of Nature Management Geography, Faculty of Exact \& Natural Sciences, Tbilisi State University, 0179, Georgia \\ ${ }^{4}$ Departments of Hydrology, Oceanology and Meteorology, Faculty of Exact and Natural Sciences, Tbilisi State University, 0179, Tbilisi, Georgia}

${ }^{*}$ Corresponding Author Email : lia.matchavariani@tsu.ge

Key words

Georgia,

Natural experiments,

Reservoir,

Silting prism

Publication Info

Paper received : 25.10 .2016

Revised received : 24.06.2017

Accepted : 28.06.2017

\section{Abstract}

Aim: The process of the sediment accumulation in reservoirs stops after the silting prism is formed on the body of equilibrium bed, by means of which the river can transport a full range of sediment downstream. Presently, there is no approved method for forecasting the parameters of the silting prism and the equilibrium bed. In order to study the process of the silting prism formation and the equilibrium channel forecasting the field experiments were carried out on small mountain rivers of Georgia.

Methodology: Methodology of the natural experiment implementation was created. For the analysis of the obtained results the methods of mathematical statistics and differential calculus were applied.

Results: The experiments showed that equilibrium bed is formed much higher than the initial position of the riverbed causing a serious threat of catastrophic inundation in case of flood. It was found that final result of the reservoir silting is an accumulative terrace, where an equilibrium channel is produced. Length of the train is a function of the maximum flow discharge, the deposit of runoff, diameter of bottom sediment and initial inclination of riverbed. Fractional distribution of the sediments into silting prism is determined by the type of the reservoir regulation and the intraannual distribution of the fluvial sediments.

Interpretation: The mechanism of riverside destruction by water flow is considered as a random process, which depends on both the effect of flow rate and riverside stability. Vulnerability, the characteristic of the riverside is taken as the indicator of this process with respect to such influence, and famous model "load - stability" from the theory of reliability is used for its identification.

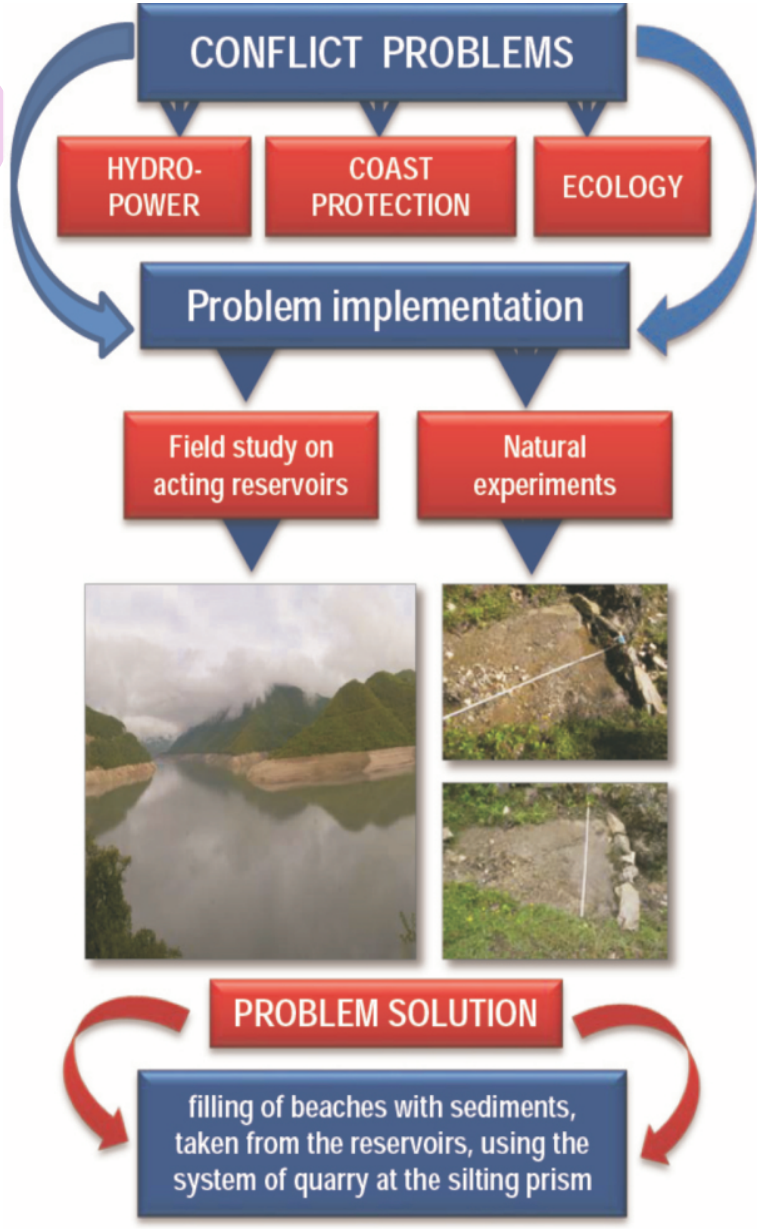




\section{Introduction}

Georgia, as a seaside mountain country, faces three opposing issues: hydropower development, coastal protection, and flooding risks. Present climate change will even more strengthen processes of beach abrasions and mountain reservoir sedimentation. High values of mountain reservoirs condition the construction of these facilities worldwide. A selection of their location occurs according to their characteristics, and due to this fact is ignored the threat of a possible catastrophic flood of riparian settlements and infrastructure. In seaside countries, the construction of reservoirs causes a heavy deficit of beachforming sediments. Mentioned negative aspects are the result of the lack of corresponding knowledge. During designing project developers don't take into account rising of water level in beds of tributaries located above the reservoir.

Presently, a basic attention is focused on the accumulative processes taking place in headrace of the water reservoirs, since this issue has not been studied before. Special interest in accumulative processes going on in the headrace is caused by the fact that without studying those processes it is impossible to identify the settlement and communication lines occurring in the zone of catastrophic water floods and to assess the proper risks. Another important reason is that mentioned negatives appear in the middle phase of operation, becoming dramatic and sometimes tragic only after expiration of the reservoir lifetime.

Sediments accumulated in the water reservoirs, i.e. silting prism consist of two growing parts. The first one is formed right in the reservoir, and the other, the train, is accumulated in the tributaries. The growth of the second one causes water level rise in the riverbed until the silting prism reaches its maximum limit. After that the accumulative processes in the headrace completely cease. In such a condition, on the surface of the silting prism an equilibrium bed of the river is developed, the parameters of which (length L and slope I) are so big that the river can completely move the sediments to the tailrace.

It is very difficult, expensive and timeconsuming to study the silting prism and equilibrium channel formation processes and parameters on the reservoirs under exploitation. Therefore, in the process of selecting the reservoir location the possible negative aspects are completely ignored. This problem is not sufficiently highlighted either in Georgian or in the foreign scientific and technical literature. Consequently, in the process of selecting the location for a reservoir the interests and safety of the population in the reservoir headrace are not taken into consideration, the volume and fractional composition of the accumulated sediments are not defined and the risks of the seashore abrasion caused by lack of sediments are not assessed. The methods of avoiding those negatives or adaptation to them are not elaborated.
Natural experiments are highly effective means for assessing the processes of the solid material accumulation and the riverbed changes in the reservoirs and tributaries as well as for filling up the lack of knowledge. To this end, some artificial reservoirs should be constructed allowing completely to study the processes of the silting prism and the equilibrium bed formation in less than two years and to determine functional relations between their parameters and hydrological-hydraulic characteristics of the river. The results obtained will allow us to elaborate appropriate recommendations for avoiding the mentioned negatives or for adapating to them.

\section{Materials and Methods}

Since the 30s of the last century, the sedimentation of reservoirs has been studied all over the world including Georgia. Lots of papers are published regarding the reservoir sedimentation, monitoring, and balancing (Amitrano et al., 2013; Ali et al., 2014), ecology and sustainability (Detering and Schuettrumpf, 2014) comparative analysis and assessment (Hajji et al., 2014; Bennett et al., 2013; Garg \& Jothiprakash, 2013; Wisser et al., 2013; Andredaki, et al., 2014; Gopinath et al., 2014), methodology and management (Hosseinjanzadeh et al., 2015; Dewals et al., 2012), reservoirs modeling and silting prism dynamic (Caputo and Carcione, 2013; Mattheus, 2013; Mansikkamäki, 2013), avoiding the effect on the environment and the catastrophic water floods (Ran et al., 2013; Metreveli \& Matchavariani, 2016; Matchavariani et al., 2016), research on the experiment of reservoir water treatment (Zhang et al., 2016), etc.

The following methods were applied in the study: the method of the natural experiment on small artificial reservoirs; field method for a long-operated reservoirs (operating for several decades); and the methods of mathematical statistics.

For spatio-temporal study of the processes of the silting prism and equilibrium channel formation the method of natural experiments was used. We selected three small rivers: Ru and Ruchula from the southern slope of the Caucasus Range tributaries of the Rioni river (Racha region) and Vere from the northern slope of the Small Caucasus Range - tributary of the Kura river (near Tbilisi city). There were constructed the dams of one meter height on these rivers. The flooded sections of the rivers were covered with the network for stationary observation of the riverbed deformation (Fig. 1). The network covered a part of the reservoir and the mouth of the tributaries. Measurement of the silting prism and its train (continuation of the silting prisms above the normal level) was made taking into consideration the frequency of the floods and freshet of the tributaries.

Field studies were carried out on long-operated reservoirs: Gumati (constructed at the Rioni River in 1953, West Georgia), Sioni (at the lori River, 1963, East Georgia), Jinvali (at 

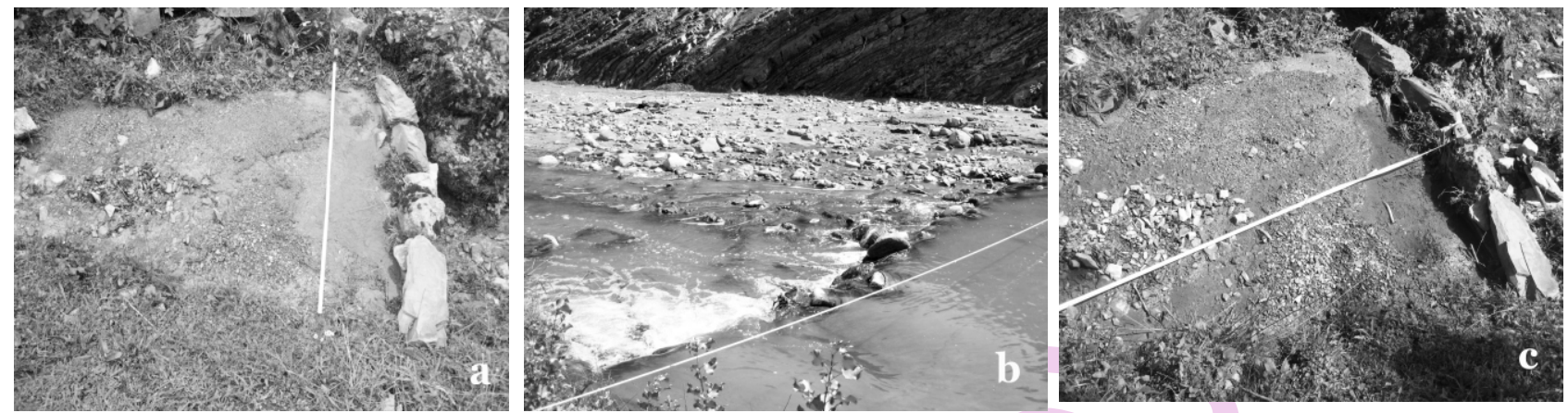

Fig. 1 : Natural experiments at the rivers Ru, Ruchula, Vere

the Aragvi River, 1986, East Georgia) using a GPS-receiver Leica GS08 connected to the network of the National Agency of Public Registry and providing a high precision of geodetic measurements throughout the country.

For the analysis of the results obtained the methods of mathematical statistics (least square method) and differential calculus were used. Approbation of the calculation results were implemented at Gumati, Sioni and Jinvali reservoirs.

Field experiments showed that the reservoir silting is most intensive in the first phase of operation, when a major part $(r \geq 70 \%)$ of the tributary sediments and solid materials formed due to the riverbank deformation are deposited. In the water reservoirs and tributaries the silting prism is formed simultaneously, though in different rates (Fig. 2). Sediment fractions (clay - fine sand), the hydraulic size of which in turbulent medium $U \leq 1.0 \mathrm{~m} / \mathrm{sec}$, are transported by streams in the initial phase of operation throughout the whole water reservoir. A part of them forms a layer in the size correspondinging to the type of the reservoir regulation. The other part of such fractions $(\geq 30 \%)$ does not take part in formation of the prism, since it is transported to the tailrace by the outlet water. In this phase, the detritus (coarse sediments) is sporadically transported to the tailrace during the emergency water outlet.

The experiment showed that the rate of the silting prism growth is diminishing - the average annual volume (rs) of the materials precipitated in water reservoir and tributaries is the biggest in the initial phase of operation decreasing in the second and third phases. Finally, it becomes equal to zero, when the silting prism reaches its limit value: $\lim _{\text {n }}{ }_{T} r_{s}=0$.

Temporary distribution $\left(r_{u}\right)$ of the sediment transported from the water reservoir is a controversial process. It is gradually increasing and at the end of the reservoir operation, i.e. after $T$ time (in years), is equal to the average annual volume $(R)$ of sediments $\left(r_{u}=R\right)$, and the sediment together with the outlet water moves to the tailrace: $\lim _{n \text { a } \mathrm{T}} r_{\mathrm{u}}=R$, where, $r_{\mathrm{s}}$ andr ${ }_{u}$ are the average annual volumes $\left(\mathrm{m}^{3} / \mathrm{year}\right)$ of the sediments precipitated in reservoirs and tributaries and transported by the stream to

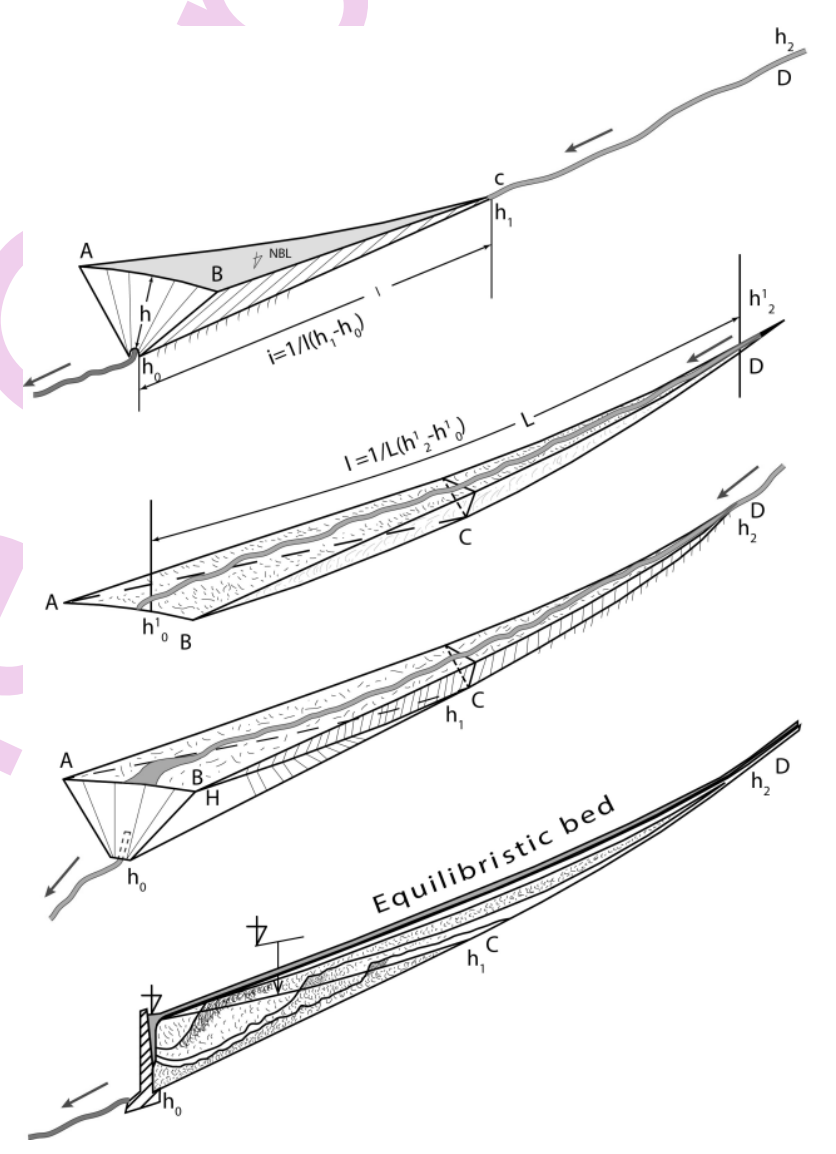

Fig. 2 : Transformation of the silting prism and the equilibrium bed in reservoirs

I-Initial phase of the reservoir and the tributary;

II-Part of the silting prism with its train above the reservoir:

III-The silting prism and equilibrium bed on the surface;

IV - Longitudinal section of the silting prism in the limited phase (as terrace)

tailrace, respectively. $R$ is the annual volume ( $\mathrm{m}^{3} /$ year) of the sediments brought by tributaries to the water reservoir, $T$ is the duration of the water reservoir operation time (years), while $\mathrm{n}=1,2, \ldots, \mathrm{T}-1, \mathrm{~T}$. 
The equilibrium bed starts above the initial riverbed, at the height ( $h, m$ ) of the dam outlet (Fig. 2), follows the silting prism surface and ends at the imaginary cross section, above which the river permanently keeps its natural ability of sediment transportation. Equilibrium channel length $(\mathrm{L})$ and slope $(1 \%)$ determine the value of the silting prism surface area $(F)$. By means of these parameters calculation of $F$ value in any phase of equilibrium bed development is possible. The equilibrium bed was formed under the Erie low, which is very important for mountain rivers: $d^{3} y=A v^{6}$. Here, $d^{3} y$ is the weight of the deposit, $v-$ flow velocity ( $\mathrm{m} / \mathrm{sec}), A$ - proportional coefficient. The process of the silting prism and equilibrium bed formation proceeded in the rate corresponding to the ratio (W/V) of their useful capacity (W) and annual amount of sediments $(\mathrm{V})$.

In the limit state the silting prism surface is a plain inclined towards the dam, which begins from the dam outlet. Its area significantly (sometimes fe"60\%) exceeds the reservoir surface. In tributaries it is extended up to the cross section, where the reservoir water flood curve reaches during the floods and freshets. The sizes of the silting prism bench basically depend on the hydrological and hydraulic characteristics of the tributaries: the bench length $(L)$, dam outlet height $(h)$, sediment diameter (d), maximum discharge of water and sediment $\left(Q_{m}, R_{m}\right)$, inclination of the bed located above the water reservoir $(1 \%): L=f\left(h, Q_{m}, R_{m}, d, I^{-}\right.$ $\left.{ }^{1}\right)$.

The length of the equilibrium bed is inversely proportional to the inclination of the river section (1\%o) located above the reservoir. It means that the more the riverbed is inclined, the shorter is the equilibrium bed. According to the experimental results, the length of the latter $(L)$ does not exceed the double length of the reservoir $(2 S): L d " 2 S$.

The experiment showed that for the population and infrastructure above the water reservoir the water flood risks are increasing in proportion to the height of the silting prism and its bench. The more space the bench occupies in the riverbed, the higher is the probability of the river overflow. The simplest approximated form of the equilibrium bed is a straight line. If the river crosses the tectonic fault line, its form comes closer either to the convex or to the concave curve. In such a case it may be described by coordinates of the parabola begining from the dam outlet and up to the imaginary cross section.

\section{Results and Discussion}

Natural experiments were used for the first time in Georgia. Similar studies were not carried out before there. The experiments were tested on Gumati and Sioni reservoirs, since the silting prism and the equilibrium bed were nearest to the limited values. Sediments accumulated in Gumati reservoir and riverbed, located above it over the decades, according to scientific sources (Metreveli et al., 2004; Iordanishvili I. \& lordanishvili K., 2012), raised the Rioni riverbed level so that every year it overflows the banks and submerge adjacent settlements and infrastructure. The territory adjacent to Sioni reservoir is in a more dangerous situation, where the sediments precipitated above the water reservoir raised the riverbed by 3-5 meters and the lori River overflowed the protective structures several times heavily damaging the riverine area, while it seemed the settlements were reliably protected with the dam (lordanishvili I. \& Iordanishvili K., 2012). Our studies showed that currently, about $98 \%$ of Gumati reservoir is occupied by sediments, while Sioni reservoir has already lost approximately $75 \%$ of its volume. Both reservoirs are located in the active tectonic zone of the southern slope of the Greater Caucasus. As of 2015, the silting prism bench changed the riverbed parameters in these reservoirs (approx. by 5-6 meters at Gumati and 2-3 meters at Sioni reservoir) so that every year during floods and freshets these rivers overflow their banks causing damage to the settlements, infrastructure and environment. Calculations based on the results of the natural experiments predict that in the nearest future the silting prism and riverbed parameters will still change by $15-20 \%$ posing a real risk of disaster to neighboring settlements. Consequently, the probability of catastrophic floods and related risks are so high that floods usually repeated in every two decades (Pe"5-10\%) has become a serious threat to the population and environment.

The silting prism formation begins from the very moment a reservoir is operated and ends in formation of an accumulation terrace. During this process the coarse-fraction sediments precipitate in the movement zone of the flood curve - near the mouth of a tributary and above it. A part of the fine- grained sediments distributed by the flow throughout the reservoir forms an accumulative layer and the rest follow the outlet water to the tailrace.

Usually, fractional distribution of the sediments in the silting prism is determined by the type of the water reservoir regulation and the intra-annual distribution of the fluvial sediments. The sediment diameter in the silting prism increases from the area of the reservoir flood curve movement (from the headwater to mouth of the tributaries) to the imaginary crosssection reducing from that area to the dam. Silting prism is characterized by the sediment foliation and drastic variation of its diameter both in vertical and horizontal directions. Therefore, in allocation of the network of the sediment extraction quarries throughout the reservoir that principle should be taken into consideration.

A great number of technically easily accessible beachforming materials of Gumati reservoir can be used to recharge the degrading seashore. Transportation of this material along the coastline is recommended by railway and special courts. From the environmental and economic point of view it is very beneficial to fill the degraded beaches with the silting material removed from 
the reservoirs. In addition, periodic cleaning of the reservoirs will increase the useful volume of water that can also contribute to the efficient development of hydropower.

The most effective way for saving the operating parameters of the reservoir and preventing the deficiency of the beach-forming material on the coast is to create a quarry system at the reservoirs and to transport the deposit to the seashore, according to the proposed trajectory, allowing to solve the coastal protection and hydropower problems in an economically profitable way without any ecological damage.

\section{Acknowledgment}

This study is funded by Shota Rustaveli National Science Foundation within the scope of grant "Modern Methods of the Joint Problem Realization for Shore Protection and Hydropower" (\#AR/220/9-120/14).

\section{References}

Ali, Y.S.A., A. Crosato, Y.A. Mohamed, S.H. Abdalla and N.G. Wright: Sediment balances in the Blue Nile River basin. Inter. J. Sediment Res., 29, 316-328 (2014).

Amitrano, D., G. Di Martino, A. lodice, D. Riccio, G. Ruello, M.N. Papa, F. Ciervo and Y. Koussoube: High resolution SAR for monitoring of reservoirs sedimentation and soil erosion in semi-arid regions. Geosciences and Remote Sensing Symposium (IGARSS), IEEE International, pp. 911-914 (2013).

Andredaki, M., A. Georgoulas, V. Hrissanthou and N. Kotsovinos: Assessment of reservoir sedimentation effect on coastal erosion in the case of Nestos River, Greece. Inter. J. Sediment Res., 29, 3448 (2014).

Bennett, S.J., J.A. Dunbar, F.E. Rhoton, P.M. Allen, J.M. Bigham, G.R. Davidson and D.G. Wren: Assessing sedimentation issues within aging flood-control reservoirs. Rev. Engin. Geol., 21, 25-44 (2013).

Caputo, M. and J.M. Carcione: A memory model of sedimentation in water reservoirs. J. Hydrol., 476, 426-432 (2013).

Detering, M. and H. Schuettrumpf: Reservoir siltation and ecological life span of dams. Wasser Wirtschaft, Springer, 104, 30-33 (2014).

Dewals, B., F. Rulot, S. Erpicum, P. Archambeau and M. Pirotton: Longterm sediment management for sustainable hydropower. Compreh. Rene. Ener., 6, 355-376 (2012).

Garg, V. and V. Jothiprakash: Evaluation of reservoir sedimentation using data driven techniques. Applied Soft Computing, 13, 35673581 (2013).
Gopinath, G., M.K. Ashitha and K.V. Jayakumar: Sedimentation assessment in a multipurpose reservoir in Central Kerala, India. Environ. Earth Sci., 72, 4441-4449 (2014).

Hajji, O., S. Abidi, H. Habaieb and M.R. Mahjoub: Regionalization and contribution to the study of reservoir sedimentation: Lakes of Cape Bon and the Tunisia Central.11th International Conference on Hydroscience \& Engineering "Hydro-Engineering for Environmental Challenges”, Germany, Proceeding, pp. 575-582 (2014).

Hosseinjanzadeh, H., K. Hosseini, K. Kaveh and S.F. Mousavi: New proposed method for prediction of reservoir sedimentation distribution. Inter. J. Sedi. Res., 30, 235-240 (2015).

Iordanishvili, I.K. and K.D. Iordanishvili: Issues of mountain reservoirs eco-evolution of Georgia. Institute of Water Industry, GTU, Tbilisi, 186c. (2012).

Mansikkamäki, $\mathrm{H} .:$ Monthly sedimentation in some reservoirs of hydroelectric stations in Finland. Fennia-Int. J. Geograp., 143, (2013).

Matchavariani, L., G. Metreveli, L. Lagidze and N. Paichadze: Siltation Problem of Mountainous Reservoirs and its Solution for Sustainable Hydropower. $16^{\text {th }}$ International Multidisciplinary Scientific Geo Conference \& Expo SGEM2016. Proceedings, book 3 "Water Resources, Forest, Marine \& Ocean Ecosystems", vol. 1 "Hydrology \& Water Resources", Albena, Bulgaria, 661-667 (2016).

Mattheus, C.R. and M.S. Norton: Comparison of pond-sedimentation data with a GIS-based USLE model of sediment yield for a small forested urban watershed. Anthropocene, Elsevier, 2, 89-101 (2013).

Metreveli, G.S., D.N. Kereselidze and Sh.D. Rehviashvili: The dynamic of silting prism of mountain reservoirs. Dynamics and Thermic of rivers, reservoirs and sea coastal zone. Proceedings of the $\mathrm{VI}$ Conference, IWP RAS, Moscow, 70-73 (in Russian) (2004).

Metreveli, G., L. Matchavariani: Research Method of Silting the Mountain Reservoirs Under the Current Climate Change. Journal of Water Resources and Ocean Science. Science Publishing Group, 5, \#2, 22-27 (2016)

Ran, L., X.X. Lu Z. Xin and X. Yang: Cumulative sediment trapping by reservoirs in large river basins: A case study of the Yellow River basin. Global Plan. Chang., 100, 308-319 (2013).

Wisser, D., S. Frolking, S. Hagen and M.F. Bierkens: Beyond peak reservoir storage? A global estimate of declining water storage capacity in large reservoirs. Water Res. Res., 49, 5732-5739 (2013)

Zhang, L., P. Zhang, M. Wang, K. Yang and J. Liu: Research on the experiment of reservoir water treatment applying ultrafiltration membrane technology of different processes. J. Environ. Biol., 37, 1007-1012 (2016). 